\title{
A stated-preference study of the willingness-to-pay to reduce traffic risk in urban vs. rural roads
}

\author{
Constantinos Antoniou
}

Received: 10 October 2012 / Accepted: 16 May 2013 / Published online: 28 June 2013

(C) The Author(s) 2013. This article is published with open access at SpringerLink.com

\begin{abstract}
Purpose The objective of this paper is to investigate the impact of the road environment (urban vs. rural) in the willingness-to-pay to reduce traffic risk.

Methods The process is based on state-of-the-art econometric models (ordered probit and random effects ordered probit models), using data from a stated preference survey, with separate scenarios for urban and rural roads. The theoretical constructs of "willingness to pay to reduce a fatality" (WTPF) and "value of (statistical) life" (VOSL) are used.

Results The WTPF for the rural area is found 3.6 times higher than for the urban environment. This finding is consistent with the literature and can be interpreted as a higher perception of traffic risk associated with rural trips over urban trips. When the WTPF is weighted by the traffic volume, this difference is reduced to 1.85 times higher VoSL for rural over urban trips.

Conclusions The estimated values of statistical life seem somewhat high compared to other estimates around the world. However, they are consistent with similar studies in Greece. The VOT for the two cases is similar and has a reasonable magnitude, suggesting that the WTPF/VOSL differences are not due to a major discrepancy in valuation of rural vs. urban trips.
\end{abstract}

Keywords Road safety · Value of statistical life · Value of preventing a fatality $\cdot$ Stated-preference surveys $\cdot$ Ordered probit $\cdot$ Random effects ordered probit

\section{Introduction}

Road safety is one of the leading causes of loss of life globally, with approximately 1.3 million fatalities each year

\section{Antoniou $(\bowtie)$}

National Technical University of Athens, School of Rural and

Surveying Engineering, 9, Iroon Polytechniou St., Zografou

Campus, Athens 15780, Greece

e-mail: antoniou@central.ntua.gr on the world's roads, and between 20 and 50 million more, who sustain non-fatal injuries [56]. In 2011, approximately 30100 people were killed in the EU27 (European Union of 27 countries) as a consequence of road collisions. Overall, 2011 was a year with mixed developments in road safety in Europe [21]. While several countries continued the positive trends of 2010 and 2009, others, including Estonia, Cyprus, Malta and road safety role models, like Sweden, Germany and Finland, saw increased numbers of road fatalities [21].

In spite of steady improvement during the last decade, Greece is still by far the worst performing country among the older European Union (EU) Member States, with more than double the fatalities per million inhabitants than the EU average in 2008 [57, 58]. Having said that, the number of road crash fatalities in Greece has dropped significantly in recent years [from 1456 in 2009 to 1141 in 2011, NRSO [39]]. While part of this improvement may be due to road safety advances, it is noted that at least part of this decrease should be attributed to the reduction in exposure due to the ongoing debt crisis in Greece [6]. Furthermore, an investigation of the spatial distributions of accidents and fatalities in Greece can be found in Papadimitriou et al. [41].

The analysis of the number of accidents and accident severity between urban and rural areas may lead to some interesting observations. Using data from the Hellenic Statistical Authority (statistics.gr), processed by the National Technical University of Athens (NTUA) Road Safety Observatory [40] one can deduce that in 2010 in Greece more than three quarters of road accidents and $49 \%$ of fatalities occurred inside built-up areas. However, accident severity is more than 4 times higher outside built-up areas [40]. This is not a new finding, as it has been described several times over the past two decades (e.g. [11, 13]). Theofilatos et al. [51] analyze the factors affecting accident severity inside and outside urban areas in Greece. Theofilatos et al. [51] conclude that factors affecting road accident severity only inside urban areas include young driver age, intersections and collision 
with fixed objects, while factors affecting only severity outside of urban areas include weather conditions and head-on and side collisions. Clark and Cushing [17] present an analysis and discussion of rural and urban traffic fatalities, correlating them with exposure and population density. The majority of the variation $(91 \%)$ in rural mortality rate was explained by rural vehicle kilometers traveled (VKT) per capita, population density and southern location. Urban mortality rate, on the other hand, was not affected by population density, but was higher in the south.

One practical approach for the estimation of traffic accident cost is the concept of the Value of Statistical Life (VOSL, [20, 31-33, 43]) or equivalently the value of preventing one traffic fatality (VPF, for a recent review c.f. [2]). Although the attempt to estimate the value of a life is a sensitive issue, such investigations take place daily in economic science, both individually and collectively. This value typically refers to the amount of money, which someone is willing to exchange for a small change in the probability of survival.To reduce potential bias coming from subjective feelings and personal criteria, the value of life used is anonymous and therefore characterized as statistical. The amount of money that a group of people collectively spends on saving one life from risk is called Value of Statistical Life (VOSL) [12].

The objective of this paper is to investigate the differences of the road environment in the willingness-to-pay to reduce traffic risk, and -therefore- to estimates of the VOSL. The process is based on state-of-the-art econometric models (ordered probit and random effects ordered probit models), using data from a stated preference survey. This research complements previous research on the topic, as it applies the same methodology to two types of roads (urban and interurban in this case; which-to the best of our knowledge- has only been performed before by [25]) and it demonstrates the practicality and benefits of using advanced econometric models for this type of analysis (again, similar to [25]). Furthermore, this research provides insight into the willingness-to-pay-to-reduce-traffic-risk literature in Europe, as it is based on data from Greece, which are arguably very different than those from Australia (where the data used in [25], were collected).

The remainder of this paper is structured as follows. Following a review of the literature, the theoretical framework is presented. The methodological framework then follows, along with the results of survey-based studies conducted in Greece, aimed at quantifying the differences in the willingness-to-pay to reduce traffic risk due to the road environment (urban vs. rural). An application of the developed models is presented. Finally, conclusions from this research, as well as directions to apply these findings are also presented.

\section{Measuring the willingness-to-pay to reduce traffic risk}

A recent overview of the topic of measuring the value of preventing a fatality can be found in Andersson and Treich [2], where various alternative approaches to estimate the social value of saving a life are presented (e.g. the human capital and annuities approach and the use of the marginal rate of substitution between risk and cost). Savage [50] presents another interesting approach to estimate the willingness to pay, in which the respondents were asked to divide a fixed sum (presumably a charitable donation of $\$ 100$ ) between research into reducing the risks for four hazards (airplane accident research, household fires research, car accident research and stomach cancer research). A review of the literature (summarized in this section) reveals that the majority of research in this field employs questionnaire-based surveys. The advantages of this type of data collection include the relatively low cost of collecting the data, the flexibility offered and the ability to design experiments with specific properties, in order to collect data suitable for the task at hand. For example, in the case of this particular research, a specially designed questionnaire allows the researcher to collect data for different types of road environments. Furthermore, the data collected by questionnaires can be used to specify and estimate powerful models (such as those developed in this research). When data are quantified in this way, they can be used to compare across different data sets obtained from properly designed questionnaires.

The data that can be used to model user behavior and attitudes are commonly split into revealed preference (RP) and stated preference (SP) data [36]. An advantage of the use of RP data to estimate demand equations is that they are consistent with market behavior [49] and economic theory has been built for dealing with real market choices (e.g. [34, 37]). Viscusi and Aldy [54] present a review of RP studies to estimate VPF, using compensating wage differentials, as well as individual consumption decisions (e.g. [7, 23, 30]).

SP data, on the other hand, come from hypothetical experiments, which has several advantages (besides the obvious disadvantage of not reflecting real choices). Louviere et al. [36] identify (and elaborate upon) the following opportunities offered by SP data: (i) SP data allow researchers to collect data about hypothetical or unavailable options or attributes, (ii) explanatory variables may have little variability or be highly collinear in the real world, (iii) SP surveys can be designed to eliminate, or at least significantly limit, data quality issues that might cause RP data to violate some of the assumptions of the models in which they are used and (iv) the products in question might not be traded in real markets (as, of course, is the case for the value of preventing a fatality, which is the topic of this research). Louviere et al. [36] treat key related topics in 
detail, such as the combination of SP and RP data to combine the benefits of both, while eliminating the associated shortcomings, as well as the design of SP surveys so that they are consistent with random utility theory.

More than one ways can be used to elicit preferences using hypothetical preferences from SP data. Stated-choice approaches have been used by e.g. Rizzi and Ortúzar [45-47] and [29]. Another approach is to use the contingent valuation (CV) method (CVM), e.g. Mitchell and Carson [38], Bateman et al. [8], Andersson and Lindberg [1], Andersson and Svensson [3]. Essentially, individuals are asked directly to indicate the amount that they would be willing to accept (or pay) for a change in the quantity or quality of a good. Beattie et al. [9] provide a critical view on CVM use for safety.

There is not a lot of literature comparing estimates of value of statistical life or risk reduction in urban vs. rural environments. De Blaeij et al. [19] indicate that it would be ideal to investigate whether there are significant differences in VoSL estimates within and between urban and rural areas. One of the stated reasons is the difference in the types of accidents between urban and rural areas [55]. The only study that was found that explicitly compared the WTP for risk reduction in urban vs. rural settings is Hensher et al. [25].

Hensher et al. [25] present the results of a stated choice experiment, based on which the authors develop mixed logit models and use the model estimates to develop VoSL estimates for different road types. In particular, the authors consider an urban and a rural area and find that the average WTP for a reduction per death in an urban car setting is about four times lower than that for the rural setting ( $\$ 0.92$ per car trip compared to $\$ 3.99$ respectively). The authors indicate that the higher estimates of WTP for non-urban settings are plausible as there is a perception of greater risk associated with rural streets. It is noted that since the AADT for rural areas is much lower, however, the values of risk reduction (VRR) obtained for the two environments are essentially the same (about \$6.3million in 2007 values).

\section{Methodology}

This section outlines the main methodological components that are used in this research. The approach that was selected is a stated-preference questionnaire-based survey. The advantages of this approach include the ability to develop a wide range of scenarios, in order to describe the situations of interest (e.g. urban/rural trips) elicit the desired responses and the fact that it enables the use of econometric models for the estimation of the willingness-to-pay.

\subsection{Experimental design}

The generation of the scenarios considered three fundamental variables for the trip in question:

- $\operatorname{Cost}(€)$;

- Risk (fatalities per year); and

- Time (minutes).

A fractional factorial design [36], which is based in differences (similar to the setup used by Rizzi and Ortúzar, [45]) was used. The advantage of using differences, rather than the actual values, when developing the scenarios is that this (differences) is what matters when estimating discrete choice models (as discussed by e.g. [28]). Each scenario included two alternatives, and three difference levels for each of the three attributes were considered, which lead to 27 possible combinations, thus generating the scenarios.

These design decisions were made in order to keep each scenario manageable and with a small number of information elements, in order to allow the respondent to be able to fairly quickly comprehend the setup of each scenario. In order to avoid overload of the respondents (that could result-among other issues- to a deterioration of the quality of the responses) the 27 scenarios were split randomly into three blocks and each respondent was only presented with one of these groups. This strategy is similar to that used in many other studies, e.g. Rizzi and Ortúzar, [4, 45].

However, differences are not directly meaningful to respondents. Therefore, the difference levels were attached to reasonable reference level values. For example, a base travel cost was calculated using estimates of car cost elements (including fuel consumption, maintenance and capital costs). The alternatives were then constructed by adding the difference levels to the reference level: e.g. Alternative $2=$ Alternative 1 (=Reference level $)+$ Difference level 1. It is noted that this process could be extended to include longer (and/or shorter) trips. However, increasing the number of levels for each attribute would increase the number of scenarios and would therefore require a different sampling strategy.

\subsection{Questionnaire design}

In order to conduct the stated-preference survey, a six-part questionnaire was designed. The questionnaire was organized in the following sections:

I. Questions setting the scene for the urban part of the survey, getting the respondent to think about the most recent urban trip they did;

II. Presentation of the (nine) scenarios relating to urban areas; 
III. Questions setting the scene for the interurban part of the survey, getting the respondent to think about the most recent interurban trip they did;

IV. Presentation of the (nine) scenarios relating to interurban areas;

V. Questions of general traffic behavior and road safety perceptions of the respondents;

VI. Questions about socio-economic characteristics of the respondents.

These six parts are outlined next. Following a short introduction in the objectives of the study, in the first part (i) the respondents were asked to think of the trip they most often do within urban areas and answer a few related questions (trip purpose, frequency the trip is done per week, average trip duration, etc.).

The next step (ii) included the statistical design for the choice experiment in the urban setting. The two alternatives were then presented to the respondents, who were asked to rate their preference for either one in a sevenlevel rating scale [35]. The respondents were told that the average annual daily traffic (AADT) in the considered route is $30,000 \mathrm{veh} /$ day. Table 1 presents an example of the format that was used to present the scenarios to the respondents.

These two parts were then repeated for the rural case (as parts (iii) and (iv)): i.e. the respondents were asked to think of the most frequent interurban trip they do in part (iii) and answer to some related questions, while a number of related scenarios were presented to them in the fourth part. Again, an experimental design of 27 scenarios was created, which was split to three blocks of 9 questions each and a single block was presented to each respondent. The respondents were told that the average annual daily traffic (AADT) in the considered route is $15,000 \mathrm{veh} /$ day.

The last two parts of the questionnaire ((v) and (vi)) included some general questions related to the road safety perceptions and the experience of the drivers (e.g. whether they have been involved in traffic accidents with or without injuries/as drivers or passengers, whether they feel road safety measures in Greece are adequate, how many people they think die in Greece in traffic crashes per year) and socioeconomic data, respectively.

\subsection{Data collection}

It is noted that the same respondents were presented with both the urban and rural scenarios, and therefore the responses are comparable. This resulted in a questionnaire that was longer than desired. The risk of lower completion rate was accepted in order to make sure that the responses for both cases (urban vs. rural) could be obtained from the same respondents. The candidate respondents were briefed in advance about the expected duration of the questionnaire (30 to $40 \mathrm{~min}$ ). During a pilot phase, 30 questionnaires were collected. The objective of this pilot was to do a preliminary analysis of the collected data to confirm that there are no design problems with the questionnaire. Preliminary models were developed using the data from the pilot phase to assess the quality of the results and identify potential issues with the questionnaire design and the obtained results indicated that the collected data were consistent with expectations. Following this, the main data collection effort started, resulting in 100 collected questionnaires (i.e. 900 observations for urban and 900 observations for rural settings, as each respondent was presented with 9 scenarios for each).

The developed questionnaire was disseminated through face-to-face interviews, in which the respondents were handed a hard copy of the questionnaire and were asked to complete it according to the instructions. The presence of a skilled interviewer during the procedure was often helpful in answering questions and providing clarifications. The respondents were approached randomly. Caution was taken to preserve an as-random-as-possible sample. For example, the location of the interviews changed frequently.

Table 2 presents some key demographic characteristics of the sample against the general Greek population (using the

Table 1 Sample scenario (urban trip)

\begin{tabular}{|c|c|c|c|c|}
\hline Daily traffic: 30,000 veh & Alternative $\mathrm{A}$ & \multicolumn{3}{|c|}{ Alternative B } \\
\hline Total travel cost (Euro) & $0.6 €$ & \multicolumn{3}{|c|}{$1.5 €$} \\
\hline $\begin{array}{l}\text { Total in-vehicle travel time } \\
\text { (min) }\end{array}$ & $30 \mathrm{~min}$ & \multicolumn{3}{|c|}{$15 \mathrm{~min}$} \\
\hline $\begin{array}{l}\text { Total number of fatalities } \\
\text { from traffic crashes per } \\
\text { year (only with passenger } \\
\text { vehicles) }\end{array}$ & 3 fatalities & \multicolumn{3}{|c|}{2 fatalities } \\
\hline \multicolumn{5}{|c|}{ Please indicate your preference below: } \\
\hline Certainly A & Possibly A & Possibly B & Probably B & Certainly B \\
\hline
\end{tabular}


Table 2 Key demographic characteristics of the sample (source: Hellenic Statistical Authority - statistics.gr)

\begin{tabular}{llll}
\hline Variable & Values & Survey & 2001 Census \\
\hline Age & $<19$ & - & $22 \%$ \\
& $20-29$ & $33 \%$ & $15 \%$ \\
& $30-39$ & $35 \%$ & $15 \%$ \\
& $40-49$ & $21 \%$ & $14 \%$ \\
& $50-59$ & $7 \%$ & $11 \%$ \\
Gender & $60-69$ & $4 \%$ & $12 \%$ \\
& $70+$ & - & $11 \%$ \\
\multirow{3}{*}{ Marital status } & Male & $52 \%$ & $49.5 \%$ \\
& Female & $48 \%$ & $50.4 \%$ \\
& Single/Divorced & $60 \%$ & $39.6 \%$ \\
& Married & $40 \%$ & $49.9 \%$ \\
& Other & - & $10.5 \%$ \\
\hline
\end{tabular}

2001 Census data, since unfortunately the data from the 2011 Census were not yet available at the time of writing). While there are some deviations, the sample covers the population reasonably well (with the exception of those below 19 years old, which is expected as people without driver's license, which in Greece can be obtained at the age of 18 , were excluded from the study). The main difference seems to relate to the age distribution, as younger people seem to be overrepresented, while older people form a smaller fraction of the sample. This is in turn reflected also in the marital status distribution; there are more single people in the sample, than there are in the general population. These deviations of the sample from the entire population should be considered when generalizing the results obtained from this analysis.

\subsection{Data analysis}

Respondents in surveys are often asked to express their preferences in a rating scale. Such scales are often called Likert scales [35, 44]. A multinomial logit model could be specified with each potential response coded as an alternative. However, the ordering of the alternatives violates the independence of the errors for each alternative, and therefore the Independence for Irrelevant Alternatives (IIA) assumption of the logit model. Nested or cross-nested models are one approach to overcoming this issue [10], while multinomial probit models also do not suffer from this limitation. Ordered logit and probit models provide another approach that estimates parameter coefficients for the independent variables, as well as intercepts (or threshold values) between the choices.

While each of these types of models has different advantages and disadvantages, in the present research the randomeffects ordered probit model was selected. Probit is selected over logit as it is more general, e.g. in terms of the covariance structures that it can represent. The ordered specification is chosen over a standard multinomial or nested specification as it explicitly considers the ordered nature of the responses (while a simple probit model could be specified in a way that one alternative is similar to those close to it and less similar to those further away, this is a less natural representation). The random-effects portion has been selected as it allows taste variation among respondents and can capture the correlation between the responses of the same individual [52].

Figure 1 shows the distribution of the choice probability $P$ as a function of the utility $U$. Assuming a ranking scale with seven levels (like the one used in Fig. 1), there are six thresholds or critical values ( $\mathrm{k} 1$ through $\mathrm{k} 6$ ) that separate the seven choices ("Certainly A", "Probably A", "Possibly A", "Indifferent", "Possibly B", "Probably B", "Certainly B"). For example, respondents choose the alternative "Certainly $\mathrm{A}$ " if the utility is below $\mathrm{k} 1$, alternative "Possibly $\mathrm{A}$ " if the utility is between $\mathrm{k} 1$ and $\mathrm{k} 2$, and so on.

In the ordered probit models that have been specified in this research, the ordered response is used directly as the dependent variable. In each model, the response variable takes numerical values between 1 and 7 , with 1 indicating that the respondent is stating that he would certainly choose alternative $\mathrm{A}$ and 7 indicating that the respondent would certainly choose alternative $\mathrm{B}$.

If $\mathrm{Y}$ is the response factor with $\mathrm{K}$ levels, the model can be written as:

$P(Y \leq k \mid x)=\Phi\left(\theta_{j}-\beta^{\prime} x\right)$

where:

- $\Phi$ is the cumulative normal function,

- $\theta_{0}=-\infty<\theta_{1}<\cdots<\theta_{k}=\infty$ are the breakpoints,

- $x$ is the vector of the explanatory factors, and

- $\quad \beta$ is the vector of the unknown parameters.

As mentioned above, the data used in this research involve repeated observations from each individual. When dealing with such panel data it is often useful to consider the heterogeneity across individuals, often referred to as unobserved heterogeneity. In general, pooling data across

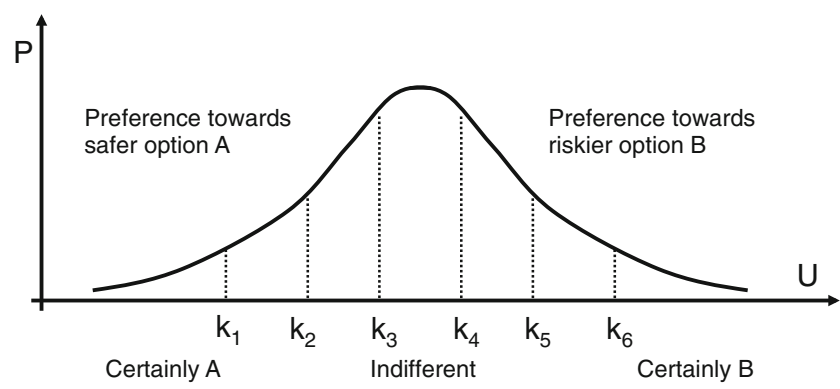

Fig. 1 Distribution of the respondents' preference (adapted from [52]) 
individuals while ignoring heterogeneity (when it is present) will lead to biased and inconsistent estimates of the effects of pertinent variables [26]. Several approaches have been developed to incorporate these effects in the model formulation.

One such approach is to estimate a constant term for each individual and each choice, which is referred to as a "fixed-effects" approach [15]. However, this implies that the model then includes a large number of parameters and consequently a large number of required observations per individual is required for its estimation. A more tractable approach is to assume that the fixed term varies across individuals according to some probability distribution, which is referred to as a "random effects" specification $[26,27]$. In this latter case, only a single parameter is added to the model specification. As a result, there are not particularly large sample size requirements. Furthermore, widely available statistical software packages can be used to estimate these models nowadays. Therefore, this approach (random effects specification) has been selected for consideration in this research.

\subsection{Marginal rates of substitution}

One of the ways to estimate the value of statistical life or value of risk reduction from stated choice experiments is through the concept of marginal rates of substitution, i.e. how much would the respondents be willing to spend to prevent one traffic fatality (i.e. the rate at which they are willing to substitute money to save one life).

Suppose the following general formulation for the systematic component of the utility function is used:

$\mathrm{V}=\beta_{0}+\beta_{\text {cost }}{ }^{*}$ travel_cost $+\beta_{\text {time }}{ }^{*}$ travel_time $+\beta_{\text {risk }}{ }^{*}$ risk $+\ldots$.

where $\beta_{i}$ are the coefficients to be estimated, travel_cost, travel time and risk are the variables associated with travel cost, travel time and risk respectively and "..." corresponds to additional explanatory parameters in the model. The coefficient of the cost and the coefficient of the travel time capture the sensitivity of the travelers' utility towards changes in the travel time and the cost. Their ratio can therefore be used to capture the trade-off between the travel time and the travel cost; in other words the value-of-time. The following explanation provides some more insight into this. The utility is in general unit-less. To simplify notation, it is sometimes useful to express it in an imaginary unit of "utils". Assuming that the travel cost is measured in $€$ and the travel risk is measured in fatalities, the units of the respective coefficients would then be utils/€ and utils/fatality respectively.
The ratio of the coefficient for the risk over the coefficient for the travel cost would have units of $€ /$ fatality, which is the expected unit for a VPF measure. Equation (2) presents the formula for the willingness to pay to reduce a fatality (WTPF):

$$
W T P F=\frac{\beta_{\text {risk }}}{\beta_{\text {cost }}} \quad\left(\frac{\text { utils } / \text { fatality } / \text { trip }}{\text { utils } / \epsilon}=\epsilon / \text { fatality } / \text { trip }\right)
$$

Equation (3) presents the formula for VPF:

$V P F=\frac{\beta_{\text {risk }}}{\beta_{\text {cost }}} \cdot$ exposure $\quad\left(\frac{\text { utils } / \text { fatality }}{u t i l s / €}=€ /\right.$ fatality $)$

where exposure is a measure of the traffic volume in the network of interest. The ratio of the estimated parameter coefficients reflects the perception of a single person. However, this has to be scaled to the general population in order to be able to be translated into a meaningful measure of money to be spent to prevent a fatality. The exposure figure is related to the way that the survey is setup. For example, if risk is expressed in fatalities per year and the scenario assumes that the average annual daily traffic (AADT) is 15,000 vehicles, then this number needs to be multiplied by 365 to obtain an annual flow. Another way to relate fatalities to exposure would be to use the number of passengers passing through the road daily. Assuming an average occupancy rate of e.g. 1.2 passengers/vehicle ([22]), such a number could be obtained from AADT. The choice of AADT in this context is made because this is something that can be easily measured (e.g. by traffic counters or the toll plaza receipts).

The ratio of the coefficient for the travel time over the coefficient for the travel cost would have units of $€ / \min$ (or $€ / \mathrm{hr}$ if multiplied by 60 ), which is the expected unit for a value-of-time (VOT) measure:

$$
\text { VOT }=\frac{\beta_{\text {time }}}{\beta_{\text {cost }}} \cdot 60 \quad\left(\frac{\text { utils } / \mathrm{min}}{\text { utils } / €} 60=€ / h r\right)
$$

\section{Model estimation results}

The models have been implemented and estimated in the $\mathrm{R}$ language for statistical computing version 2.15.1 ([48]), with the pglm package [18] for model estimation. The model specification started with a simple model, including only the main variables of travel cost, time and risk, and incrementally adding parameters that were expected to prove relevant. The incremental model building was driven both by the significance of the estimated parameter 
coefficients, as well as the summary goodness of fit measures, such as log-likelihood and AIC.

Table 3 presents the model estimation results for urban roads, while Table 4 presents the estimation results from rural roads. For each case, two models are presented: the finally selected ordered probit and the respective random effects ordered probit model. The main difference between the models lies in the standard deviation of the random effect, which obviously is only relevant in the latter model. If the standard deviation of the random effect is statistically significant, then there is evidence that there is heterogeneity across the population and therefore the random effects probit model can be chosen over the base ordered probit model. Indeed, for the urban case the standard deviation of the random effect is statistically significant at the $95 \%$ confidence level, while for the rural case it is statistically significant at the $99.9 \%$ confidence level.

It is important (for the interpretation of the models) to indicate that, following the data collection and prior to the estimation of the models, the data have been processed, so that the alternative with the higher risk is always the first one. Observations, for which the first alternative had lower risk, have been reversed, so that during the data analysis the first alternative has the higher risk. This is required in order for the model estimation results to be interpretable. Since the models use the difference of the utilities, subtracting the second from the first utilities implies a positive risk, and the estimated coefficients should be interpreted keeping this observation in mind. For example, estimated coefficients with larger (positive) value would imply that they would be associated with safer choices. This reordering was not performed prior to presenting the original questionnaire to the respondents, as it could lead to biased responses (e.g. from respondents with a higher tendency to ceteris paribus choose the first alternative). Choosing a different processing rule (e.g. re-arrange the alternatives so that the first one is always the cheaper or shorter one) would result in models capturing different aspects of the data. While the core results should not change, the interpretation of the estimated parameter coefficients would.

With the exception of the age variables for the random effects ordered probit model for the urban case, which are significant well above the $90 \%$ level, the retained parameters in the final models are significant at the $95 \%$ level (with
Table 3 Estimated models for urban roads

\begin{tabular}{|c|c|c|c|c|}
\hline \multirow{2}{*}{$\begin{array}{l}\text { Urban } \\
\text { Variables }\end{array}$} & \multicolumn{2}{|c|}{ Ordered probit } & \multicolumn{2}{|c|}{ Random effects ordered probi } \\
\hline & Estimate & $t$ value & Estimate & $t$ value \\
\hline Intercept & 1.244 & 6.574 & 1.257 & 6.204 \\
\hline Travel cost (Euro) & -1.203 & -9.918 & -1.219 & -9.957 \\
\hline Travel time (min) & -0.077 & -10.885 & -0.078 & -10.923 \\
\hline Risk & -0.288 & -8.636 & -0.292 & -8.686 \\
\hline Married & 0.210 & 2.404 & 0.212 & 2.234 \\
\hline Duration ( $<30 \mathrm{~min}, 30-45 \mathrm{~min},>45 \mathrm{~min})$ & 0.186 & 3.093 & 0.188 & 2.874 \\
\hline Age $>60$ y.o. & 0.392 & 2.000 & 0.398 & 1.864 \\
\hline Age $<35$ y.o. & 0.166 & 1.941 & 0.168 & 1.804 \\
\hline Accidents as driver in urban: $>1$ & -0.404 & -3.806 & -0.409 & -3.543 \\
\hline Injury accident as a driver & -0.335 & -3.480 & -0.339 & -3.326 \\
\hline Injury accident as passenger & 0.266 & 2.302 & 0.267 & 2.130 \\
\hline \multicolumn{5}{|l|}{ Threshold parameters for index model } \\
\hline mu_1 & 0.674 & 9.649 & 0.681 & 9.610 \\
\hline mu_2 & 0.857 & 11.602 & 0.867 & 11.529 \\
\hline mu_3 & 1.713 & 20.498 & 1.736 & 19.977 \\
\hline mu_4 & 2.441 & 27.480 & 2.470 & 26.474 \\
\hline mu_5 & 2.932 & 31.288 & 2.964 & 30.039 \\
\hline \multicolumn{5}{|l|}{ Standard deviation of random effect } \\
\hline Sigma & & & 0.210 & 2.047 \\
\hline \multicolumn{5}{|l|}{ Summary statistics } \\
\hline Number of observations & 900 & & 900 & \\
\hline Initial log-likelihood & -1583.59 & & -1583.59 & \\
\hline Final log-likelihood & -1500.65 & & -1499.99 & \\
\hline AIC & 3033.29 & & 3033.99 & \\
\hline
\end{tabular}


Table 4 Estimated models for rural roads

*Having been given the information that the speed limit is $120 \mathrm{kmh}$

\begin{tabular}{|c|c|c|c|c|}
\hline \multirow{2}{*}{$\begin{array}{l}\text { RURAL } \\
\text { Variables }\end{array}$} & \multicolumn{2}{|c|}{ Ordered probit } & \multicolumn{2}{|c|}{ Random effects ordered probit } \\
\hline & Estimate & $t$ value & Estimate & $t$ value \\
\hline Intercept & 1.875 & 13.798 & 1.982 & -12.779 \\
\hline Travel cost (Euro) & -0.309 & -7.201 & -0.316 & -7.302 \\
\hline Travel time (min) & -0.022 & -8.781 & -0.022 & -8.822 \\
\hline Risk & -0.266 & -8.078 & -0.278 & -8.364 \\
\hline Chosen speed in Freeways $*>120 \mathrm{kmh}$ & -0.214 & -2.929 & -0.228 & -2.302 \\
\hline Accidents as driver in urban: $>1$ & -0.478 & -4.809 & -0.512 & -3.814 \\
\hline Involved in accident as driver & 0.487 & 5.316 & 0.520 & 4.217 \\
\hline \multicolumn{5}{|l|}{ Threshold parameters for index model } \\
\hline mu_1 & 0.847 & 8.448 & 0.892 & 8.474 \\
\hline mu_2 & 1.122 & 10.704 & 1.186 & 10.732 \\
\hline mu_3 & 1.976 & 17.769 & 2.096 & 17.560 \\
\hline mu_4 & 2.510 & 22.088 & 2.654 & 21.593 \\
\hline mu_5 & 3.167 & 26.899 & 3.333 & 26.039 \\
\hline \multicolumn{5}{|l|}{ Standard deviation of random effect } \\
\hline Sigma & & & 0.450 & 5.900 \\
\hline \multicolumn{5}{|l|}{ Summary statistics } \\
\hline Number of observations & 900 & & 900 & \\
\hline Initial log-likelihood & -1557.09 & & -1557.09 & \\
\hline Final log-likelihood & -1487.49 & & -1478.37 & \\
\hline AIC & 2998.98 & & 2992.73 & \\
\hline
\end{tabular}

most of them being significant at least at the $99 \%$ and $99.9 \%$ levels). The signs and magnitudes of all estimated coefficients are consistent with expectations; cost, travel time and risk have negative values (as they all reflect the disutility of travel).

The presented questionnaire included a seven-level rating scale, so one would expect six threshold parameters (k1 through k6, as in Fig. 1). For model estimation reasons, however, in the presented results there is one intercept presented, along with five threshold parameters (mu_1 through mu_5). To obtain the original six parameters one needs to perform a simple manipulation: $\mathrm{k}_{1}=$ intercept, $\mathrm{k}_{2}=$ intercept + $\mu_{1}=\mathrm{k}_{1}+\mu_{1}, \mathrm{k}_{3}=$ intercept $+\mu_{1}+\mu_{2}=\mathrm{k}_{2}+\mu_{2}$ and so on. For example, for the ordered probit model for the urban case, $\mathrm{k}_{1}=1.244, \mathrm{k}_{2}=1.244+0.674=1.918, \mathrm{k}_{3}=1.244+0.674+$ $0.857=2.775$ and so on.

While no explicit analysis of the effects of the survey design on subgroups of the population has been performed in this research, the differentiation between subgroups of respondents can be inferred from the model parameters, which can be interpreted as follows. A positive coefficient for married respondents implies that these drivers would have a higher propensity to choose the safer alternative; a finding consistent with the literature [14]. Similarly, older ( $>60$ years old) respondents show the highest propensity to choose the safer alternative, a finding consistent with self-regulatory behaviors of older drivers [16]. Young ( $<35$ years old) respondents follow with a somewhat lower propensity towards the safer option, while the remainder of the population (i.e. those between 35 and 60 years old) exhibit a higher propensity towards the riskier option.

Properties of the duration of the typical trip that the authors make, as well as attributes related to the road safety experience of the drivers, are also considered. The longer the duration of the typical trip, the higher the propensity of the driver to choose the safer alternative. This can be attributed to an effort of the drivers to compensate for the increased exposure of longer trips. However, drivers that have experienced more than one accident as a driver in urban areas and those who have experienced an injury accident as a driver show a higher propensity for the riskier alternative. This could be attributed to the "desensitization" of these drivers to the prospect of having an accident, after having experienced one (or more) accident(s) as drivers. Accidents in urban areas usually involve lower speeds, and therefore have less severe implications. Respondents who have experienced an injury accident as a passenger, on the other hand, show a higher propensity to choose the safer alternative, i.e. the opposite effect from when they experience accidents as drivers. This might be related to the differences in perception of accidents experienced as driver vs. as a passenger. In particular, drivers feel more in control of the vehicles, than passengers. Therefore, the shock of an accident to the driver 
is arguably lower; this effect can be strengthened by the fact that -while drivers in general may "see an accident coming"-, it is not unlikely for passengers to be caught by surprise by an accident, leading to a larger shock (which in turn affects their future behavior in a stronger way).

The estimated parameter coefficients of the random effects ordered probit model are very similar to those obtained by the ordered probit model. Furthermore, the estimated coefficient for the standard deviation of the random effect is very significant, indicating that indeed there was some heterogeneity in the population that could not be captured by the ordered probit model. From a more global point of view, the AIC and final log-likelihood values of the two models are comparable, thus not providing a clear indication as to which model is superior.

Table 4 presents the estimated model results for the data using scenarios with rural roads. The estimated values of the intercept, threshold parameters and the parameters for travel cost, time and risk are similar to those for the urban case, and so is their interpretation. However, the parameters that proved significant and were thus included into the final model specification are somewhat different. Respondents that choose to speed on freeways show a higher propensity to choose the riskier alternative, an intuitive finding. Those that have experienced more than one accident as driver in urban areas also show a tendency towards the riskier alternative, which is the same effect that was obtained for the models for the urban case (Table 3), and the same rationale can be used to interpret this variable.

The coefficient estimate associated with the dummy variable of whether a respondent is involved in an accident as a driver, however, implies that those that are (involved in an accident as drivers) show a tendency towards the safer option in rural roads. This is the opposite effect from the variable of whether a respondent is involved in an injury accident as a driver for the urban case, and can be interpreted as being due to the perception of higher speeds in rural roads.

\section{Calculation of marginal rates of substitution}

Table 5 summarizes the main marginal rates of substitution that can be computed from the estimated models. Three values are computed based on each model: WTPF, VoSL and VOT. Several interesting observations can be made, based on this information. First, the ordered probit and random-effects ordered probit models do not show different results. Furthermore, the VOTs are rather similar, implying that this difference in valuation is not the result of a major discrepancy in valuation of rural vs. urban trips. The magnitude of the estimated VOT is also interesting, as it is reasonable for Greece in the midst of the debt crisis, when compared to values such as those estimated by Antoniou et al. [4], who found the VOT for interurban trips to be about 6 Euro/hour, or Polydoropoulou et al. [42] who estimated values between US\$5/hour and US\$6.6/hour.

The willingness to pay to reduce a fatality for the rural area, however, is about 3.6 times higher than the urban environment, a finding very similar to Hensher et al. [25]. This finding can be interpreted as a higher perception of traffic risk associated with rural trips over urban trips. When the willingness to pay is weighted by the traffic volume for the urban vs. rural scenario, however, and since the traffic volume that was assumed for the urban scenario is double that for the rural trip, this difference is reduced to 1.85 times higher VoSL for the rural trip over the urban trip.

\section{Application}

This section presents an application of the estimated models, in order to demonstrate their use in a practical setting. Considering a base scenario, the risk difference between the two alternatives is used as the parameter of interest. This risk difference ranges between 0.5 fatality/year and 5 fatalities/year (for the urban case) and 7 fatalities/year (for the rural case), corresponding to the range of differences used when developing the scenarios for the questionnaire. The larger difference of risk for the rural case reflects the higher risk of this type of road environment (vs. urban). The base scenario considers the following parameter values:

- Zero travel cost and travel time difference between the two alternatives;

- Married respondents;

- Medium trip duration;

- Middle age group (35-60 years old);

- Respondent involved in 1 accident as a driver in an urban environment;

- Respondent involved in 2 accidents as a driver;

- Respondent involved in 2 accidents with injury as a driver;

- Respondent involved in 2 accidents with injury as a passenger;

- Respondent selects a speed of $120 \mathrm{kph}$ in freeways.

Figure 2 summarizes the results of this application. The top figure presents the results for the urban environment, while the bottom one the corresponding results for the rural case. The x-axis of each plot represents the difference in risk, while the y-axis represents the cumulative probability of choosing between the two alternative routes. Since there are seven response levels in the estimated models (and therefore six thresholds between them), there are six curves presented in each plot (and a dashed horizontal line indicating the $100 \%$ cumulative 
Table 5 Estimated measures

\begin{tabular}{|c|c|c|c|c|}
\hline & \multicolumn{2}{|l|}{ Urban } & \multicolumn{2}{|l|}{ Rural } \\
\hline & Ordered probit & Random-effects ordered probit & Ordered probit & Random-effects ordered probit \\
\hline WTP to reduce fatality ( $€ /$ fat/trip) & 0.239 & 0.239 & 0.860 & 0.880 \\
\hline VoSL* (€/fat/year) & $2,625,000$ & $2,625,000$ & $4,710,000$ & $4,820,000$ \\
\hline VOT (€/hour) & 3.83 & 3.83 & 4.18 & 4.14 \\
\hline
\end{tabular}

*: rounded to nearest five thousand Euro

probability). At the left-most edge of the curves, where the risk difference is marginal, the probability of choosing between the two routes is rather balanced. As the risk difference increases, then the probability of choosing the safer option increases progressively.

\section{Conclusion and discussion}

This paper investigates the perceived differences in the value of preventing a fatality in urban vs. rural areas. The methodology uses data from a stated-preference questionnaire survey to
Fig. 2 Model application results

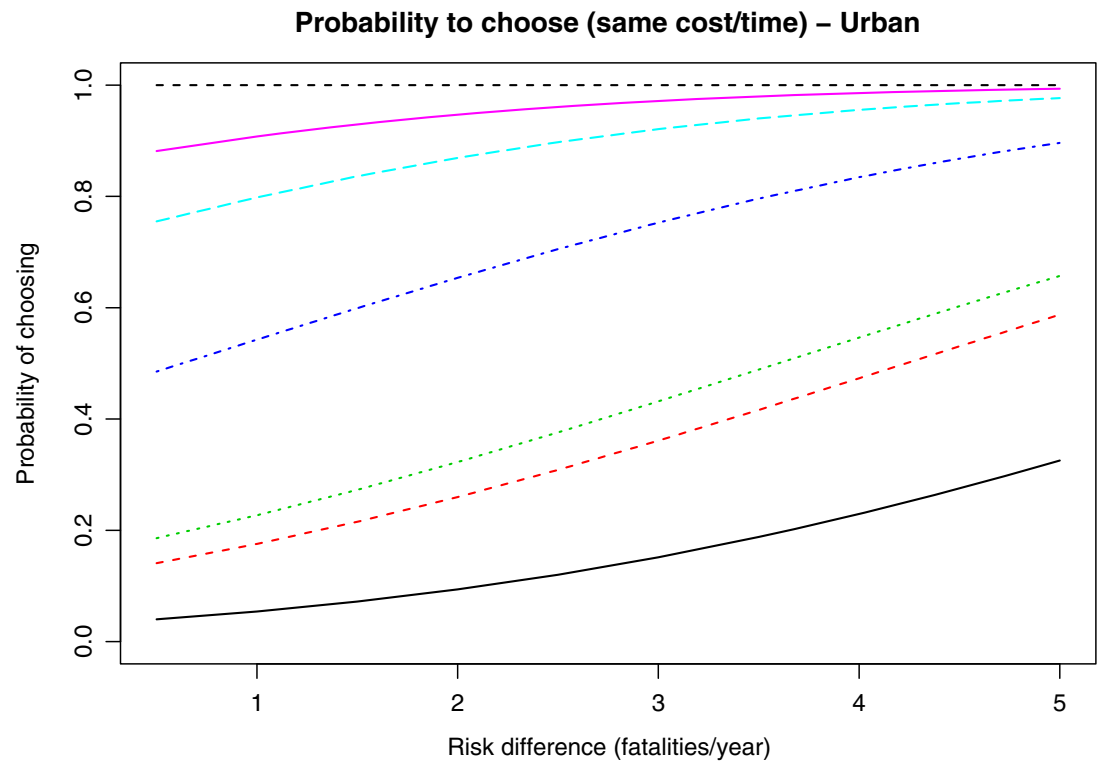

Probability to choose (same cost/time) - Rural

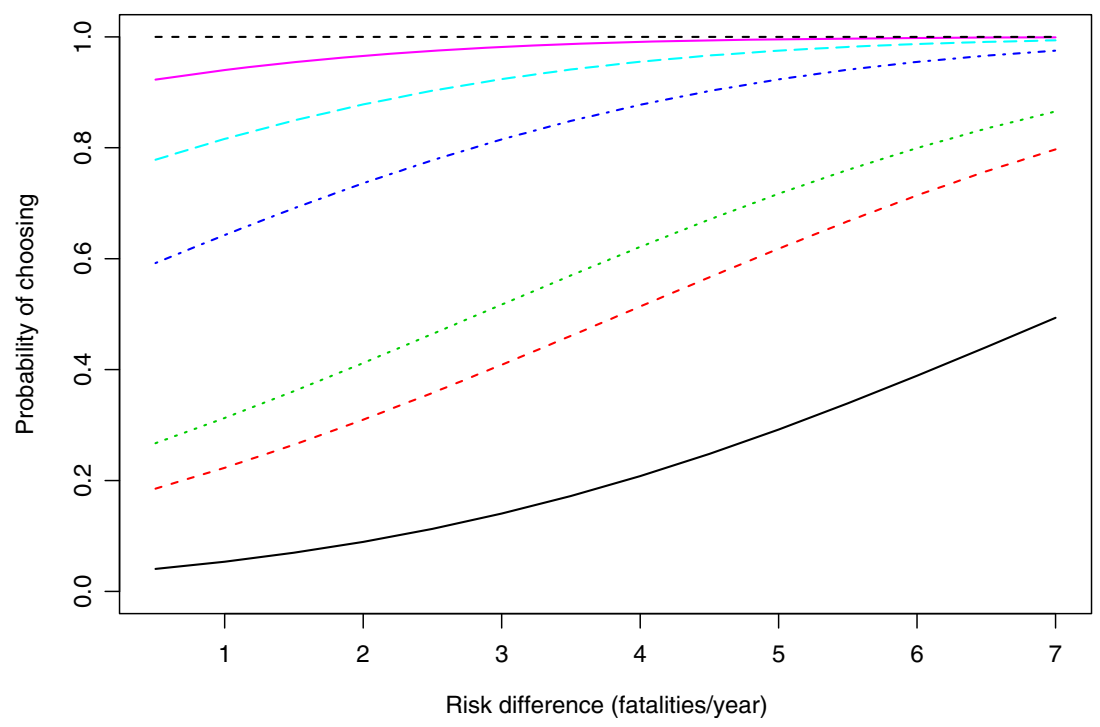


specify and estimate state-of-the-art econometric models (ordered probit and random effects ordered probit). A six-part stated-preference survey was designed, including questions on the respondents' background, their attitude towards road safety and their past involvement in accidents, as well as structured scenarios with alternative trips. The estimated model coefficients are used to calculate values of willingness to pay to reduce traffic fatalities, values of time and values of statistical life for urban and rural roads.

The estimated values of statistical life seem somewhat high compared to other estimates around the world. However, they are lower than other similar studies in Greece around the same time (such as [5]). This is, however, an intriguing finding that should be further researched. Furthermore, the estimated values of time are reasonable (especially considering the current precarious financial situation in Greece). The difference in the values of statistical life between urban and rural roads are consistent with the literature [25]. Further evidence towards the observation that this difference is true and not an artifact of valuation differences between urban and rural roads is provided by the similar estimated VOTs for urban and rural roads.

An interesting finding relates to the parameters reflecting the accident experience of the drivers, in which it is evidenced that the respondents can distinguish between accidents that occur in urban vs. rural areas, as well as accidents in which they are drivers vs. accidents in which they are involved as passengers.

Additional data and a richer model specification could further enhance the value of these models. For example, additional attributes (such as trip purpose, time of day, or day of week during which the trip in question takes place) might provide additional insight into the problem, while more than three levels for each attribute would provide additional granularity in the responses. The same could perhaps be achieved by using a 9-level Likert scale for the collection of the responses. In terms of model specification, in this model only direct effects between the parameters have been considered. Including interaction terms might provide additional insight about the combined impact of parameters. Of course, such models might require larger sample sizes to be estimated successfully.

Hammitt and Robinson [24] recommend that the calculated VPF should also be considered in the context of the average income of a society. In the developed models in this research, the income variable was not found statistically significant and therefore was not included in the model specifications. If a larger sample was available, then perhaps some additional parameters would have become statistically significant, resulting in a richer model.

Furthermore, the specific model results can be a useful tool in fine-tuning public policy and designing road safety campaigns. This finding (using the model results to guide campaigns, rather than treating the entire population as a single group) is consistent with Ulleberg [53], who suggests that (young) drivers "should not be treated as a homogeneous group pertaining to road safety". The heterogeneity of the population is an important aspect that needs to be taken into consideration, in order to avoid biased estimates. The value calculated must be carefully used between different people, always associated with the average income of a society. Random effects models, explicitly considering the heterogeneity across the population are particularly suited to such analysis.

Acknowledgments The author would like to thank Surveying Engineers Ms. Hara Vanaklioti and Mr. Ioanni Ventoura for assisting with the data collection effort.

Open Access This article is distributed under the terms of the Creative Commons Attribution License which permits any use, distribution, and reproduction in any medium, provided the original author(s) and the source are credited.

\section{References}

1. Andersson H, Lindberg G (2009) Benevolence and the value of road safety. Accid Anal Prev 41(2):286-293

2. Andersson H and Treich N (2011) The value of a statistical life. In: A Handbook of Transport Economics, A. de Palma, R. Lindsey, E. Quinet, R. Vickerman (eds), Edward Elgar Pub.

3. Andersson H, Svensson M (2008) Cognitive ability and scale bias in the contingent valuation method. An analysis of willingness to pay to reduce mortality risk. Environ Resour Econ 39(4):481-495

4. Antoniou C, Matsoukis E, Roussi P (2007) A methodology for the estimation of value-of-time using state-of-the-art econometric models. J Public Transp 10(3):1-20

5. Antoniou C and Kostovasilis K (2012) Can external stimuli affect the perceived value of statistical life? Proceedings of the 91st Annual Meeting of the Transportation Research Board, January 2012, Washington, D.C.

6. Antoniou C and Yannis G (2013) State-space based analysis and forecasting of macroscopic road safety trends in Greece. Accident Analysis and Prevention. doi:10.1016/j.aap.2013.02.039

7. Atkinson SE, Halvorsen R (1990) The valuation of risks to life: evidence from the market for automobiles. Rev Econ Stat 72(1):133-136

8. Bateman IJ, Carson RT, Day B, Hanemann M (2004) Economic valuation with state preference techniques: A manual. Edward Elgar, Cheltenham

9. Beattie J, Covey J, Dolan P, Hopkins L, Jones-Lee M, Loomes G, Pidgeon N, Robinson A, Spencer A (1998) On the contingent valuation of safety and the safety of contingent valuation: part 1caveat investigator. J Risk Uncertain 17:5-25

10. Ben-Akiva M, Lerman S (1985) Discrete choice analysis: Theory and application to travel demand. MIT Press, Cambridge

11. Bentham G (1986) Proximity to hospital and mortality from motor vehicle traffic accidents. Soc Sci Med 23:1021-1026

12. Blomquist GC (2001) Economics of value of life. In the economics section. In: Ashenfelter O, Smelser NJ, Baltes PB (eds) International encyclopedia of the social and behavioral sciences. Pergamon of Elsevier Science, New York 
13. Brodsky H, Hakkert AS (1983) Highway fatal accidents and accessibility of emergency medical services. Soc Sci Med 17:731740

14. Cassar A, Crowley L, Wydick B (2007) The effect of social capital on group loan repayment: evidence from field experiments. Econ J 117:F85-F106

15. Chamberlain G (1980) Analysis of covariance with qualitative data. Rev Econ Stud 47:225-238

16. Charlton JL, Oxley J, Fildes B, Oxley P, Newstead S (2003) Selfregulatory behaviours of older drivers. Annu Proc Assoc Adv Automot Med 47:181-194

17. Clark DE, Cushing BM (2004) Rural and urban traffic fatalities, vehicle miles, and population density. Accid Anal Prev 36(6):967-972

18. Croissant Y (2010) pglm: panel generalized linear model. R package version 0.1-0. http://CRAN.R-project.org/package=pglm

19. de Blaeij A, Florax RJGM, Rietveld P, Verhoef E (2003) The value of statistical life in road safety: a meta-analysis. Accid Anal Prev 35:973-986

20. Drèze J (1962) "L'utilité sociale d'une vie humaine." Revue Française de Recherche Opèrationelle, 6: 93-118

21. ETSC (2012) A Challenging Start towards the EU 2020 Road Safety Target. 6th Road Safety PIN Report, European Transport Safety Council, Brussels

22. European Environmental Agency (EEA) (2013) Are we moving in the right direction? Indicators on transport and environmental integration in the EU: TERM 2000 - Indicator 22-23: Vehicle Utilisation. Available online: http://www.eea.europa.eu/publications/ ENVISSUENo12/page029.html (Accessed: April 5, 2013)

23. Hakes JK, Viscusi WK (2007) Automobile seatbelt usage and the value of statistical life. South Econ J 73(3):659-676

24. Hammitt $J$ and Robinson L (2011) The income elasticity of the value per statistical life: transferring estimates between high and low income populations. J Benefit-Cost Anal, Vol.2 (1), Article 1

25. Hensher DA, Rose JM, de D Ortúzar J, Rizzi LI (2009) Estimating the willingness to pay and value of risk reduction for car occupants in the road environment. Transp Res A 43:692-707

26. Hsiao C (1986) Analysis of panel data. Cambridge University Press, Cambridge

27. Heckman J (1981) The incidental parameters problem and the problem of initial conditions in estimating a discrete timediscrete data stochastic process. In: Manski C, McFadden D (eds) Structural analysis of discrete data with econometric applications. MIT Press, Cambridge

28. Hensher DA (1990) The orthogonality issue in stated choice designs. In: Fischer M, Nijkamp P, Papageorgiou Y (eds) Spatial choices and processes. Elsevier, Amsterdam, pp 265-277

29. Iragüen P, Ortúzar JD (2004) Willingness-to-pay for reducing fatal accident risk in urban areas: an Internet-based Web page stated preference survey. Accid Anal Prev 36:513-524

30. Jenkins RR, Owens N, Wiggins LB (2001) Valuing reduced risks to children: the case of bicycle safety helmets. Contemp Econ Policy 19(4):397-408

31. Jones-Lee MW (1974) The value of changes in the probability of death or injury. J Polit Econ 82(4):835-849

32. Jones-Lee MW (1976) The value of life: An economic analysis. Martin Robertson, London

33. Jones-Lee MW (1982) The value of life and safety. North-Holland, Amsterdam

34. Lancaster K (1966) A new approach to consumer theory. J Polit Econ 74:132-157

35. Likert R (1932) A technique for the measurement of attitudes. Arch Psychol 140:55

36. Louviere JJ, Hensher DA, and Swait JD (2003) Stated choice methods: analysis and applications. Second Edition. Cambridge University Press
37. McFadden D (1981) Econometric models of probabilistic choice. In: Manski C, McFadden D (eds) Structural analysis of discrete data with econometric applications. MIT Press, Cambridge, pp 198-272

38. Mitchel RC, Carson RT (1989) Using surveys to value public goods: The contingent valuation method. Resources for the Future, Washington-DC

39. NRSO (2013a) Basic road safety figures, Greece 2001 - 2011, NTUA Road Safety Observatory, available online at: http:// www.nrso.ntua.gr/images/stories/data/nrso-basic-gr1-2011.pdf (accessed: April 5, 2013)

40. NRSO (2013b) Basic road safety figures, Road fatalities by area and road type, 2011, NTUA Road Safety Observatory, available online at: http://www.nrso.ntua.gr/images/stories/data/nrso-gr42011.pdf (accessed: April 5, 2013)

41. Papadimitriou E, Ekshler V, Yannis G, Lassarre S (2012) Modelling the spatial variation of road accidents and fatalities in Greece. Proc ICE - Transp 166(1):49-58

42. Polydoropoulou A, Kapros S, and Pollatou E (2004) A national passenger mode choice model for the Greek observatory. Proceedings of the 10th World Congress on Transportation Research (WCTR) Conference, Istanbul

43. Pratt JW, Zeckhauser RJ (1996) Willingness to pay and the distribution of risk and wealth. J Polit Econ 104:747-765

44. Richardson AJ (2002) Simulation study of estimation of individual specific values of time using adaptive stated-preference study. Transp Res Rec 1804:117-125

45. Rizzi LI, de D Ortúzar J (2003) Stated preference in the valuation of interurban road safety. Accid Anal Prev 35:9-22

46. Rizzi LI, de D Ortúzar J (2006) Estimating the willingness-to-pay for road safety improvements. Transp Rev 26(4):471-485

47. Rizzi LI, de D Ortúzar J (2006) Road safety valuation under a stated choice framework. J Transp Econ Policy 40(1):69-94

48. R Development Core Team (2013) R: A language and environment for statistical computing. R Foundation for Statistical Computing, Vienna, Austria. ISBN 3-900051-07-0, (http://www.Rproject.org/)

49. Samuelson PA (1948) Foundations of economic analysis. McGraw-Hill, Cambridge

50. Savage I (1993) An empirical investigation into the effect of psychological perceptions on the willingness-to-pay to reduce risk. J Risk Uncertain 6(1):75-90

51. Theofilatos A, Graham D, Yannis G (2012) Factors affecting accident severity inside and outside urban areas in Greece. Traffic Inj Prev 13(5):458-467

52. Train K (2009) Discrete choice methods with simulation. Second edition. Cambridge University Press

53. Ulleberg P (2001) Personality subtypes of young drivers. Relationship to risk-taking preferences, accident involvement, and response to a traffic safety campaign, Transportation Research Part F: Traffic Psychology and Behaviour, Volume 4, Issue 4 pp. 279-297

54. Viscusi WK, Aldy JE (2003) The value of a statistical life: a critical review of market estimates throughout the world. J Risk Uncertain 27(1):5-76

55. Wadhwa LC (1998) Highway safety issues in rural and urban environments -verification of community perception. J Int Assoc Traffic Safety Sci 22:79-85

56. WHO (2009) Global Status Report on Road Safety: Time for Action. World Health Organization, Geneva (www.who.int/ violence_injury_prevention)

57. Yannis G (2007) Road safety in Greece. J IATSS 31(2):110-112

58. Yannis G, Papadimitriou E (2012) Road Safety in Greece, Proceedings of Transport Research Arena, Procedia - Social and Behavioral Sciences, Volume 48, Pages 2839-2848 